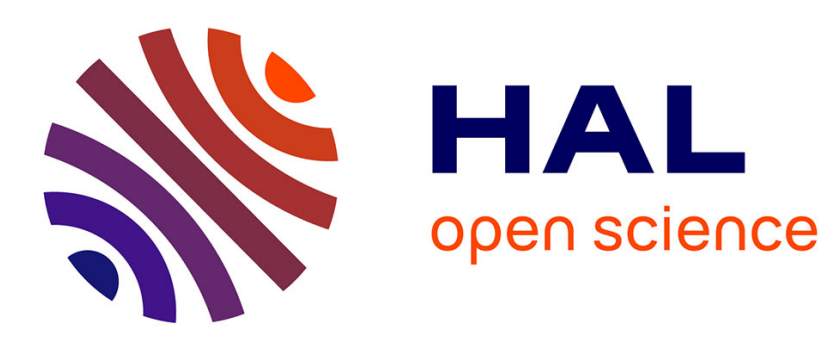

\title{
Disorder and magnetic excitations in $\mathrm{CaC} r \times \mathrm{F}$ e $2-\mathrm{x}$ $\mathrm{O} 4(\mathrm{x}=0,0.5)$
}

M. Songvilay, S. Petit, M. Koza, S. Rols, E. Suard, V. Skumryev, C. Martin, F. Damay

\section{- To cite this version:}

M. Songvilay, S. Petit, M. Koza, S. Rols, E. Suard, et al.. Disorder and magnetic excitations in CaC r x F e $2-$ x O 4 ( $\mathrm{x}=0$, 0.5 ). Physical Review B, 2020, 101 (1), pp.014407. 10.1103/PhysRevB.101.014407. hal-02998092

\section{HAL Id: hal-02998092 https://hal.science/hal-02998092}

Submitted on 5 Jan 2021

HAL is a multi-disciplinary open access archive for the deposit and dissemination of scientific research documents, whether they are published or not. The documents may come from teaching and research institutions in France or abroad, or from public or private research centers.
L'archive ouverte pluridisciplinaire HAL, est destinée au dépôt et à la diffusion de documents scientifiques de niveau recherche, publiés ou non, émanant des établissements d'enseignement et de recherche français ou étrangers, des laboratoires publics ou privés. 


\title{
Magnetic excitations in $\mathrm{CaCr}_{\mathrm{x}} \mathrm{Fe}_{2-\mathrm{x}} \mathrm{O}_{4}(\mathrm{x}=0,0.5)$
}

\author{
M. Songvilay ${ }^{1,2}$, S. Petit ${ }^{1}$, M. Koza ${ }^{3}$, S. Rols ${ }^{3}$, E. Suard ${ }^{3}$, V. Skumryev ${ }^{4}$, C. Martin ${ }^{5}$ and F. Damay ${ }^{1}$ \\ ${ }^{1}$ Laboratoire Léon Brillouin, CEA-CNRS UMR 12, 91191 GIF-SUR-YVETTE CEDEX, France \\ ${ }^{2}$ School of Physics and Astronomy and Centre for Science at Extreme Conditions, University of \\ Edinburgh, Edinburgh EH9 3FD, United Kingdom \\ ${ }^{3}$ Institut Laue-Langevin, 6 rue Jules Horowitz, BP 156, 38042 GRENOBLE CEDEX 9, France \\ ${ }^{4}$ Departament de Física, Universitat Autònoma de Barcelona, 08193 Bellaterra, Barcelona, Spain \\ ${ }^{5}$ Laboratoire CRISMAT, Normandie Univ., ENSICAEN, UNICAEN, CNRS, 14000 Caen, France
}

\section{Version : 05/01/2021}

AUTHOR EMAIL ADDRESS Manila.Songvilay@ed.ac.uk

\begin{abstract}
Polycrystalline $\mathrm{CaFe}_{2} \mathrm{O}_{4}$ and $\mathrm{CaCr}_{0.5} \mathrm{Fe}_{1.5} \mathrm{O}_{4}$ have been investigated by elastic and inelastic neutron scattering. In agreement with previous reports, $\mathrm{CaFe}_{2} \mathrm{O}_{4}$ undergoes two magnetic transitions, first to a $\mathrm{B}$ phase, below $\mathrm{T}_{\mathrm{NB}}=200 \mathrm{~K}$, then to an $\mathrm{A}$ phase, below $\mathrm{T}_{\mathrm{NA}}=175 \mathrm{~K}$, while substituted $\mathrm{CaCr}_{0.5} \mathrm{Fe}_{1.5} \mathrm{O}_{4}$ undergoes a magnetic transition to the $\mathrm{B}$ phase only, at $\mathrm{T}_{\mathrm{N}}=$ $125 \mathrm{~K}$. Each phase corresponds to staggered antiferromagnetic chains coupled either ferromagnetically (A phase) or antiferromagnetically (B phase). In the A phase of $\mathrm{CaFe}_{2} \mathrm{O}_{4}$, inelastic scattering measurements show clearly defined gapped spin waves, which can be
\end{abstract}


modelled with classical calculations, based on a simple exchange Hamiltonian following the topology of the crystal structure. In contrast, in the B phase of both compounds, the interpretation of the excitation spectrum evades completely the classical approach, even at low temperature. These results are interpreted based on an interchain exchange close to the threshold between ferromagnetic and antiferromagnetic bonding geometry. This induces random interchain coupling, thus creating magnetic exchange disorder whose dominating effect is to blur out the magnetic excitation spectrum of the B phase. A magneto-elastic effect, through which the interchain coupling becomes sizeably ferromagnetic, and which is not observed in $\mathrm{CaCr}_{0.5} \mathrm{Fe}_{1.5} \mathrm{O}_{4}$, stabilises the $\mathrm{A}$ phase at low temperature in $\mathrm{CaFe}_{2} \mathrm{O}_{4}$.

\section{INTRODUCTION}

Coexistence of magnetic phases in thermal equilibrium is a rare occurrence without a first order transition. It is more common in chemically disordered materials, however, such as $\mathrm{Mn}_{\mathrm{x}} \mathrm{Cr}_{1-\mathrm{x}} \mathrm{S}$ [1], [2]. In this case, according to De Gennes [3], finite clusters have a non-zero probability to exist above a critical concentration, hence providing a simple explanation for the coexistence of different magnetic phases. In contrast, in chemically ordered systems, the occurrence of a weak specific magnetic interaction is usually put forward to explain concomitant magnetic phases. This has been reported in $(\mathrm{Fe}, \mathrm{Mn}) \mathrm{WO}_{4}[4]$ or $\mathrm{CuMnO}_{2}[5]$ for instance. As early as 1967, magnetic phases coexistence has also been mentioned in the $S=5 / 2$ antiferromagnet $\mathrm{CaFe}_{2} \mathrm{O}_{4}$ by Corliss et al. [6] ; nevertheless, the origin of this behaviour remains an open issue, as none of the usual interpretations based on chemical disorder or weak magnetic exchange seem to hold in this compound. 
$\mathrm{CaFe}_{2} \mathrm{O}_{4}$ has an orthorhombic Pbnm structure, with a honeycomb array of $\mathrm{FeO}_{6}$ octahedra sharing edges and corners, building tunnels around $\mathrm{Ca}$ atoms. A common way to describe the iron lattice is to draw staggered Fe-O-Fe-... chains running along $b$ (Figure 1). The Fe-O-Fe bond angle being close to $130^{\circ}$, antiferromagnetic (AF) super-exchange between $\mathrm{Fe}^{3+}\left(d^{5}\right)$ is expected to be the dominant magnetic interaction [7], [8]. In $\mathrm{CaFe}_{2} \mathrm{O}_{4}$ [6], [9], [10], [11], two $\mathbf{k}=0$ collinear antiferromagnetic orders have been evidenced, termed A and B (using the same notation as in [6]). The $\mathrm{B}$ phase $\left(\mathrm{T}_{\mathrm{NB}} \sim 190 \mathrm{~K}[6]\right)$ corresponds to $\mathrm{AF} \mathrm{Fe}-\mathrm{O}-\mathrm{Fe}-\ldots$ chains stacked antiferromagnetically along $a$, while the A phase ( $\left.\mathrm{T}_{\mathrm{NA}} \sim 170 \mathrm{~K}[6]\right)$, corresponds to a ferromagnetic coupling along $a$ of those AF chains (bottom of Figure 1). Both phases coexist between $\mathrm{T}_{\mathrm{NA}} \sim 170 \mathrm{~K}$ and $\sim 130 \mathrm{~K}$, but below $130 \mathrm{~K}$, only the A phase is observed [6], [10]. In their seminal work, Corliss et al. discussed for the first time the existence of an equilibrium between the A and B phases, as well as the possibility of a nucleation process at magnetic domain boundaries, remarking on the fact that nuclei of the A phase are generated at the domain boundaries of the B one, and vice versa. Very recently, spectroscopic experiments performed on $\mathrm{CaFe}_{2} \mathrm{O}_{4}$ single crystals have shown the existence of discrete low energy levels, attributed to isolated spin clusters associated with antiphase boundaries [12], [13], concurringly with Corliss' picture. In $\mathrm{CaFe}_{2} \mathrm{O}_{4}$, a domain wall boundary thus corresponds to a $180^{\circ}$ flip of half the spins (i.e., one chain every two).

In the present work, we report on an investigation of a polycrystalline sample of $\mathrm{CaFe}_{2} \mathrm{O}_{4}$ using elastic and inelastic neutron scattering, combined with magnetisation measurements, which provides new clues to the coexistence of the A and B phases in this compound. We have mapped the evolution with temperature of the spin dynamics of $\mathrm{CaFe}_{2} \mathrm{O}_{4}$, to study the $\mathrm{B}-\mathrm{A}$ phase transition, and compared the results with chemically disordered $\mathrm{CaCr}_{0.5} \mathrm{Fe}_{1.5} \mathrm{O}_{4}$, in which only the B phase is observed. The most striking results are (i) very distinct excitation spectra in the A and B phases, (ii) failure to describe the dynamics of the B phase with conventional 
spin wave theory, in both $\mathrm{x}=0$ and $\mathrm{x}=0.5$ compounds, and (iii) the persistence at high temperature of quasi-elastic scattering around the Q positions of both the A and B phases magnetic Bragg peaks for $\mathrm{x}=0$ and possibly $\mathrm{x}=0.5$. To explain these features, the proposed scenario invokes random interchain coupling in the B phase. We propose that the magnetoelastic effect clearly observed in $\mathrm{CaFe}_{2} \mathrm{O}_{4}$, but lacking in $\mathrm{CaCr}_{0.5} \mathrm{Fe}_{1.5} \mathrm{O}_{4}$, regularises this interchain coupling, triggering the transition to the A phase.

\section{EXPERIMENTAL}

Polycrystalline samples were prepared starting from mixtures of $\mathrm{CaCO}_{3}, \mathrm{Fe}_{2} \mathrm{O}_{3}$ and $\mathrm{Cr}_{2} \mathrm{O}_{3}$ weighed in stoichiometric proportions and heated at $1000{ }^{\circ} \mathrm{C}$ in air. X-ray diffraction was performed to check that the samples are well crystallised and single-phase.

Neutron powder diffraction (NPD) versus temperature was performed on the G4.1 diffractometer $\left(\lambda=2.425 \AA\right.$, with a resolution $\Delta \mathrm{Q}=0.015 \AA^{-1}$ at $\left.\mathrm{Q}=1 \AA^{-1}\right)$ from 1.5 to $300 \mathrm{~K}$, at LLB-Orphée (CEA-Saclay, France). High-resolution neutron diffraction versus temperature [14] was performed on the D2B instrument $(\lambda=1.595 \AA)$, with the $10^{\prime}$ collimation, at Institut Laue-Langevin (Grenoble, France). Rietveld refinements and determination of the magnetic symmetry with representation analysis were performed with programs of the FullProf suite [15] and the Bilbao Crystallographic Server [16]. No deviation from the nominal oxygen composition was reliably refined from the high resolution neutron data.

Time-of-flight (TOF) inelastic neutron scattering experiments were performed using the cold (IN6) and thermal (IN4) spectrometers at the Institut Laue-Langevin [17]. On IN6, two incident wavelength settings were used, $\lambda_{\mathrm{i}}=4.1 \AA$ and $5.1 \AA$, and maps were recorded between $50 \mathrm{~K}$ and $230 \mathrm{~K}$. The instrumental resolution is $\sim 0.15 \mathrm{meV}$ at $4.1 \AA$, and $0.085 \mathrm{meV}$ at $5.1 \AA$. To 
get an overview of the whole excitation spectrum, maps were also recorded on IN4, between $50 \mathrm{~K}$ and $230 \mathrm{~K}$, with an incident wavelength of $1.1 \AA$ or $2.2 \AA$.

For $\mathrm{CaCr}_{0.5} \mathrm{Fe}_{1.5} \mathrm{O}_{4}$, inelastic neutron scattering experiments were also performed on the tripleaxis spectrometer 4F2 at LLB-Orphée, with $k_{\mathrm{f}}=1.97 \AA^{-1}$ (with an energy resolution of $0.2 \mathrm{meV}$ ) at $10 \mathrm{~K}$ and $70 \mathrm{~K}$. Higher order contaminations were removed with pyrolytic graphite.

Spin-wave calculations were performed using the Spinwave software developed at LLB [18]. Based on the Holstein-Primakov approximation, the code diagonalizes the chosen spin Hamiltonian ; in the present case, the calculations were performed using isotropic exchange couplings. $\mathrm{S}(\mathrm{Q}, \omega)$ is first calculated over a sphere in the reciprocal space, and powderaveraging is performed sampling the sphere following a Fibonacci based algorithm [19].

\section{RESULTS}

Crystal and magnetic structures of $\mathrm{CaFe}_{2} \mathrm{O}_{4}$ and $\mathrm{CaCr} 0.5 \mathrm{Fe}_{1.5} \mathrm{O}_{4}$

The $\mathrm{CaFe}_{2} \mathrm{O}_{4}$ crystal structure parameters (Pbnm space group, $a=10.6966(1) \AA, \quad b=9.2322(1)$ $\AA$, $c=3.0214(3) \AA$ ) refined from the $250 \mathrm{~K}$ high resolution neutron diffractogram agree perfectly with previously published results [20]. There is no structural transition according to high resolution neutron diffraction down to $1.5 \mathrm{~K}$, in agreement with Raman spectroscopy [21] on a single crystal of $\mathrm{CaFe}_{2} \mathrm{O}_{4}$.

$\mathrm{CaCr}_{0.5} \mathrm{Fe}_{1.5} \mathrm{O}_{4}$ is isostructural with $\mathrm{CaFe}_{2} \mathrm{O}_{4}$, with only a slight decrease of the cell parameters $(a=10.674(3) \AA, b=9.219(2) \AA, c=3.008(1) \AA$, from neutron diffraction data at $240 \mathrm{~K})$, owing to the reduced size of $\mathrm{Cr}^{3+}(\mathrm{S}=3 / 2)$ with regards to $\mathrm{HS} \mathrm{Fe}^{3+}(\mathrm{S}=5 / 2)$ in six-fold coordination (0.615 and $0.645 \AA$, respectively [22]).

The temperature evolution of the neutron diffraction patterns of $\mathrm{CaFe}_{2} \mathrm{O}_{4}$ is illustrated on Figure 1 (top left panel). In agreement with the properties previously reported by Corliss et al. [6], 
and in [23], $\mathrm{CaFe}_{2} \mathrm{O}_{4}$ first undergoes a magnetic transition at $\mathrm{T}_{\mathrm{NB}}=200 \mathrm{~K}$, towards the $\mathrm{B}$ phase, followed by a transition towards the A phase at $\mathrm{T}_{\mathrm{NA}}=175 \mathrm{~K}$. As mentioned in the introduction, they are both $\mathbf{k}=0$ structures, and correspond to the Shubnikov magnetic space groups $P b^{\prime} \mathrm{nm}$ (B) and $P b^{\prime} n^{\prime} m$ (A), respectively. Figure 1 clearly shows that magnetic intensities grow on distinct Bragg peaks for each phase. In particular, the most intense magnetic Bragg peak is (020) at $\mathrm{Q}=1.36 \AA^{-1}$ for the $\mathrm{B}$ phase, but (110) for the A phase, at $\mathrm{Q}=0.9 \AA^{-1}$, thus allowing an easy identification of each phase. The evolution of the ordered moment with temperature on Figure 2 (middle panel) shows that the B phase ordered magnetic moment reaches a maximum of $\sim 2 \mu_{\mathrm{B}}$ at $\mathrm{T}=175 \mathrm{~K}$, temperature at which the A phase appears. The increase of the ordered moment on the A phase is concomitant with the decrease of that of the B phase. Below $130 \mathrm{~K}$, only the A phase is observed on the neutron diffraction patterns of $\mathrm{CaFe}_{2} \mathrm{O}_{4}$, and at $1.5 \mathrm{~K}$, the A-phase ordered magnetic moment is $4 \mu_{\mathrm{B}}$, in good agreement with previous reports [24], but below the expected value of $5 \mu_{\mathrm{B}}$ for $\mathrm{Fe}^{3+}$. These ordered moment values were obtained with a constrained moment amplitude on both Fe1 and Fe2 sites, not imposed by symmetry considerations. Releasing this constraint [25] does not provide a visibly better refinement profile. Rietveld refinement of $\mathrm{CaFe}_{2} \mathrm{O}_{4}$ in its A phase $(\mathrm{T}=1.5 \mathrm{~K})$ is illustrated on Figure 1 (left bottom panel). There is no clear sign of magnetic diffuse scattering before or after the transitions, and Bragg magnetic peaks are resolution limited in both A and B phases of $\mathrm{CaFe}_{2} \mathrm{O}_{4}$. This indicates that magnetic order extends over more than $1000 \AA$, and that it is truly long-range in both phases, without any of the magnetic staking defects characteristics that can be found in low-dimensional compounds [26], at least within our instrumental resolution. In contrast to $\mathrm{CaFe}_{2} \mathrm{O}_{4}$, only one magnetic transition is observed for $\mathrm{CaCr}_{0.5} \mathrm{Fe}_{1.5} \mathrm{O}_{4}$, which corresponds to a magnetic ordering of a $\mathrm{B}$ type (Figure 1, right panels), at $\mathrm{T}_{\mathrm{NB}}=125 \mathrm{~K}$, indicated by the presence of resolution-limited magnetic Bragg peaks. This was already hinted 
at in the $\mathrm{CaCr}_{\mathrm{x}} \mathrm{Fe}_{2-\mathrm{x}} \mathrm{O}_{4}$ phase diagram reported by Corliss et al. [6]. In that case, the ordered moment value reaches $3 \mu_{\mathrm{B}}$ at $1.5 \mathrm{~K}$ (Figure 1), again far below the expected value of $4.5 \mu_{\mathrm{B}}$. A difference in the magnetic behaviours of the two compositions is also revealed in the macroscopic properties, as shown by the magnetisation vs. temperature curve (Figure 2). $\mathrm{CaFe}_{2} \mathrm{O}_{4}\left(\mathrm{x}=0\right.$, Figure 2a) shows a large hysteresis effect at $\mathrm{T}_{\mathrm{NA}}$ with separation of the $f c$ and $z f c$ curves, in agreement with previously reported results on super-stoichiometric $\mathrm{CaFe}_{2} \mathrm{O}_{4}$ [27], and crushed single-crystals [28], [29], the $f c$ curve displaying a peak around $140 \mathrm{~K}$, concomitant with the disappearance of the magnetic Bragg peak from the B phase (see Figure 2c). This hysteresis is strongly magnetic field dependent, as mentioned in [28] and in agreement with single crystal measurements [23]. The most likely origin is from locally non-compensated moments, or canting/defects at the boundaries between magnetic domains. $\mathrm{CaCr}_{0.5} \mathrm{Fe}_{1.5} \mathrm{O}_{4}$ only features in contrast a peak shaped antiferromagnetic transition, and slight separation between the $z f c$ and $f c$ curves (Figure $2 \mathrm{~b}$ ). $\chi_{\text {ac }}$ measurements have been performed for both compositions (in the frequency range 1-1000 Hz), but did not show any magnetic relaxation feature in the temperature range between 1.5 and $250 \mathrm{~K}$ (not shown). In addition, in $\mathrm{CaFe}_{2} \mathrm{O}_{4}$, only one peak is seen on $\chi^{\prime}(\mathrm{T})$ curves, at $\mathrm{T}=175 \mathrm{~K}\left(\mathrm{~T}_{\mathrm{NA}}\right)$. This contrasts with the frequency dependence of the ac susceptibility reported in [29], which was attributed to ferrimagnetic ordering, originating from the presence of two valence states on the iron site in a $\mathrm{CaFe}_{2} \mathrm{O}_{4-\delta}(\delta=0.06)$ sample. The absence of relaxation features in our samples would therefore substantiate their O4 stoichiometry, and suggest that any fluctuations linked with magnetic defects do not occur in the $\mathrm{kHz}$ frequency range.

\section{Inelastic neutron scattering study of the A phase of $\mathrm{CaFe}_{2} \mathrm{O}_{4}$}

To follow up the diffraction and macroscopic measurements results, the evolution with temperature of the magnetic excitations spectra of $\mathrm{CaFe}_{2} \mathrm{O}_{4}$ is shown on Figure 3 and Figure 4, 
for different incident wavelengths, allowing one to investigate the whole excitation spectrum, in addition to its low energy features. At low temperature $(\mathrm{T}<130 \mathrm{~K})$, gapped magnetic excitations can be clearly seen, at Q positions only corresponding to the A phase, in agreement with the diffraction results (in particular, there is no magnetic intensity at $\mathrm{Q}=1.36 \AA^{-1}$ reminiscent of the B phase at this temperature, see Figure $4 \mathrm{~b}$ at $50 \mathrm{~K}$ ). The gap can be estimated to be around $2.5 \mathrm{meV}$ at $50 \mathrm{~K}$ (Figure $5 \mathrm{a}$ ), its evolution with temperature up to $\mathrm{T}=170 \mathrm{~K}$ is shown on Figure 5b. The high energy part of the dispersion reaches about $35 \mathrm{meV}$ (Figure 3, $1.1 \AA$ ), and the dispersion can be rather straightforwardly approached with an Hamiltonian, derived from the topology of the crystal structure, of the type :

$$
H=J_{S E} \sum_{i, j} S_{i} S_{j}+J_{a} \sum_{i, j} S_{i} S_{j}+J_{c} \sum_{i, j} S_{i} S_{j}+D_{n} \sum_{i}\left(S_{i} \cdot n\right)^{2}
$$

with $\mathrm{J}_{\mathrm{SE}}$, the super-exchange coupling along the Fe chains, $\mathrm{J}_{a}$ the coupling between chains, and $\mathbf{J}_{c}$ the magnetic exchange along $c(\mathbf{J}>0$ corresponds to an antiferromagnetic coupling of the spins). $D$ is the single-ion anisotropy ( $D$ is negative, as it accounts for an easy-axis anisotropy, with $n$ being the easy-axis direction) (see bottom panels of Figure 1 for a schematic drawing of the magnetic exchanges). All these exchanges are first-neighbour. The spin wave spectrum calculated with this simple Hamiltonian is shown on Figure 6, for $\mathrm{J}_{\mathrm{SE}}=2.5 \mathrm{meV}, \mathrm{J}_{a}=-0.1 \mathrm{meV}$, $\mathrm{J}_{c}=-1.7 \mathrm{meV}$, and $\mathrm{D}=-0.11 \mathrm{meV}$. The top of the excitation spectrum is well reproduced, as well as the magnetic intensity around $20 \mathrm{meV}$ (Figure 6), which can be adjusted by playing with the $\mathrm{J}_{\mathrm{SE}} / \mathrm{J}_{c}$ ratio. The value of $\mathrm{J}_{a}$ is found to be rather small, but can be reliably deduced from the low energy experimental data, as it is linked with the slope of the $Q=0.9 \AA^{-1}$ branch, and affects the intensities of the higher $\mathrm{Q}$ branches (Figure 6a and 6c). The $20 \mathrm{meV}$ signal at high $\mathrm{Q}$ (seen for $\mathrm{Q}>6 \AA^{-1}$ ) is a lattice phonon, as its intensity is constant over the $\mathrm{T}$ range considered when corrected by the detailed balance factor. All the features of the experimental spectrum in the A phase can be described therefore by the spin wave calculation, using the first- 
neighbour Hamiltonian (1). Note also that the Q position of the three main branches visible at low energy, below $3 \AA^{-1}$, that is, at $\mathrm{Q}=0.9,1.48$ and $2.23 \AA^{-1}$, and which correspond to the (110), (120) and (320) main magnetic Bragg peaks of the A phase, respectively (Figure 6b and 6d), are perfectly reproduced by the calculations.

Inelastic neutron scattering study of the B phase of $\mathrm{CaFe}_{2} \mathrm{O}_{4}-\mathrm{Comparison}$ with $\mathrm{CaCr}{ }_{0.5} \mathrm{Fe}_{1.5} \mathrm{O}_{4}$ Between $130 \mathrm{~K}$ and $\mathrm{T}_{\mathrm{NA}}=175 \mathrm{~K}$, a mixture of the $\mathrm{A}$ and $\mathrm{B}$ phases is expected from the diffraction data. The whole excitation spectra recorded for $\mathrm{T}_{\mathrm{NA}} \leq \mathrm{T} \leq \mathrm{T}_{\mathrm{NB}}$ (temperature range corresponding to the B phase only), with $\lambda=1.1$ and $2.2 \AA$ are illustrated on Figure 3 (middle panel), while the low energy magnetic excitations are shown on Figure 4. For $\mathrm{T} \geq 160 \mathrm{~K}$ (Figure 4), there is a clear increase of the intensity at $Q=1.36 \AA^{-1}$ (which corresponds to the strongest magnetic Bragg peak of the B phase), concomitantly with a broadening in Q of the excitation at $\mathrm{Q}=0.9 \AA^{-1}$ (A phase). This broadening becomes more ostensible above $180 \mathrm{~K}$. A filling of the anisotropy gap seen in the low energy part of the branches of the A phase is also noticeable, at $\mathrm{Q}=0.9 \AA^{-1}$ and for the three branches in the $2-3 \AA^{-1}$ range, as shown by constant- $\mathrm{Q}$ cuts in Figure 5a.

Apart from the top of the spectrum, however, which is still around $35 \mathrm{meV}$ like in the A phase, the inelastic scattering data are quite distinct from the one obtained in the A phase, and dominated by the strong magnetic intensity emerging from the magnetic Bragg peak at $1.36 \AA^{-}$ ${ }^{1}$ and from the $2-3 \AA^{-1} \mathrm{Q}$ range (Figure 3). Surprisingly, there is no energy flat band in the magnetic signal ( $35 \mathrm{meV})$, as would be expected from the density of state-like spectrum of a powder-averaged excitation spectrum. In addition, it is quite clear that magnetic fluctuations from the $\mathrm{A}$ phase are still present in the spectrum of $\mathrm{CaFe}_{2} \mathrm{O}_{4}$ at $185 \mathrm{~K}$, with, in particular, a very broad gapless signal centred on $\mathrm{Q}=0.9 \AA^{-1}$ and gapless branches emerging from the $\mathrm{Q}$ positions of the main Bragg peaks of the A phase $\left(2-3 \AA^{-1}\right)$. 
To get a clearer picture -at lower temperature- of the magnetic excitation spectrum of the B phase, inelastic neutron scattering measurements were performed on $\mathrm{CaCr}_{0.5} \mathrm{Fe}_{1.5} \mathrm{O}_{4}$ at various temperatures, as shown on Figure 7. $\mathrm{E}=4 \mathrm{meV}$ cuts for both $\mathrm{x}=0$ and 0.5 compositions at various temperatures are also compared and illustrated on Figure 8a and 8b. The similarity of the data sets $(\lambda=1.1$ and $2.2 \AA)$ of $x=0$ at $185 \mathrm{~K}$ and $\mathrm{x}=0.5$ at $50 \mathrm{~K}$ is rather striking, and confirms the lack of an intensity maximum at high energy. The top of the magnetic signal reaches $30 \mathrm{meV}$ for $\mathrm{x}=0.5$, that is, slightly lower than for $\mathrm{CaFe}_{2} \mathrm{O}_{4}$. The main magnetic feature of the $\mathrm{B}$ phase is therefore a quasi-elastic like scattering emerging from $\mathrm{Q}=1.36 \AA^{-1}$, with a diffuse magnetic signal in the $2-3 \AA^{-1}$ area, which extends to high energy (Figure 7a), and whose $\mathrm{Q}$ structure is smoothed out with respect to $\mathrm{x}=0$ (Figure $8 \mathrm{~b}$ and $8 \mathrm{c}$ ). Accordingly, the three low energy branches seen in $\mathrm{CaFe}_{2} \mathrm{O}_{4}$ at $185 \mathrm{~K}\left(\mathrm{Q} \sim 2-3 \AA^{-1}\right)$, which are reminiscent of A phase excitations, are not visible in the low energy spectrum of $\mathrm{CaCr}_{0.5} \mathrm{Fe}_{1.5} \mathrm{O}_{4}$ at $10 \mathrm{~K}$ (see Figure 7b). It is also true at $70 \mathrm{~K}$ (not shown). In an attempt to check for the presence of an anisotropy gap in the $\mathrm{B}$ phase, an energy scan at constant $\mathrm{Q}=1.36 \AA^{-1}$ was performed on a cold triple-axis spectrometer (as illustrated in Figure 7c) and gives a value of $\sim 1.6 \mathrm{meV}$.

A basic attempt at modelling the B magnetic phase with the same exchange interaction values as in the A phase, except for a change of sign of $\mathbf{J}_{a}$ in Hamiltonian (1), actually leads to a rather poor agreement of the overall excitation spectrum, failing to reproduce in particular the "quasielastic"-like energy dependence of the spectrum. Whether this is due to specific magnetic fluctuations within the B phase, or from unexpected changes in the Hamiltonian, remains unanswered at this point, and will be discussed further below. However the first hypothesis is supported by unusual Mössbauer spectra in the same temperature range which was previously reported in [30], and attributed to magnetic fluctuations or super-paramagnetism. 
Comparison between $\mathrm{CaFe}_{2} \mathrm{O}_{4}$ and $\mathrm{CaCr}_{0.5} \mathrm{Fe}_{1.5} \mathrm{O}_{4}$ in their high temperature regime above $\mathrm{T}_{N B}$

In $\mathrm{CaFe}_{2} \mathrm{O}_{4}$, well above $\mathrm{T}_{\mathrm{NB}}$, at $230 \mathrm{~K}$, persisting quasi-elastic features are still observed in a broad range of $\mathrm{Q}$, between 0.9 and $1.36 \AA^{-1}$, although with less intensity, and with a rapidly decreasing correlation length as $\mathrm{T}$ increases (Figure 8a). A similar observation holds for $\mathrm{x}=$ 0.5 (Figure 8b). Moreover, the $4 \mathrm{meV}$ profiles (above $\mathrm{T}_{\mathrm{NB}}$ ) of $\mathrm{x}=0$ (at $230 \mathrm{~K}$ ) and $\mathrm{x}=0.5$ (at $150 \mathrm{~K}$ ) are remarkably similar, with, in particular, the presence of a shoulder around $Q=0.9 \AA^{-}$ ${ }^{1}$ in $\mathrm{x}=0.5$, as well as $\mathrm{x}=0$ (Figure $8 \mathrm{~d}$ ). This $\mathrm{Q}$ position being related to A type ordering, this could suggest that magnetic fluctuations of the A type are also present in $\mathrm{CaCr}_{0.5} \mathrm{Fe}_{1.5} \mathrm{O}_{4}$ at temperatures above its magnetic ordering to the B phase but below its paramagnetic regime.

\section{DISCUSSION}

From the diffraction data, it is confirmed that there are two magnetic phase transitions in $\mathrm{CaFe}_{2} \mathrm{O}_{4}$, first to a $\mathrm{B}$ phase, then to an $\mathrm{A}$ phase, with coexistence of both over a narrow temperature range. In $\mathrm{CaCr}_{0.5} \mathrm{Fe}_{1.5} \mathrm{O}_{4}$, there is only one magnetic transition, towards the $\mathrm{B}$ phase. The fact that a quasi-elastic signal at Q positions characteristic of each phase is seen, well above $\mathrm{T}_{\mathrm{NB}}$, but below the paramagnetic regime, in both compounds, does, however, preclude the usual phase transition picture.

The coexistence of two phases in equilibrium within $\mathrm{CaFe}_{2} \mathrm{O}_{4}$ is a forthright hypothesis [6]. As mentioned in the introduction, this coexistence has also been seen in a single crystal, and interpreted as an incomplete stacking of the A and B phases [12]. Interesting dynamical effects originate from the defects described in [12], as localised excitations in regions one or two cell wide along $a$. These effects have not been seen in the present work, even on high-resolution $\mathrm{E}$ scans at constant $\mathrm{Q}$, on either the A or B phase. Moreover, this relies on a scenario in which 
there is nucleation of the B phase at the boundaries of A, which does not match the diffraction data of the present study : there is no sign in the diffraction patterns of the short range order expected in the case of magnetic clusters with short correlation length stemming from domain walls. A possible explanation for the discrepancy with [12] is that these defects could fluctuate in a time window different from the frequency range probed by neutrons $(\mathrm{THz})$ and the $a c$ susceptibility measurements $(\mathrm{kHz})$. Such fluctuations may also account for the reduced ordered moment refined in the A phase. Further measurements are planned to explore the intermediate time scale, using muon spectroscopy. Furthermore, in the present study, the high resolution neutron inelastic data at $50 \mathrm{~K}$ shown in Figures $4 \mathrm{~b}$ and $6 \mathrm{~b}$ display a quasi-elastic feature at low temperature, stemming from $\mathrm{Q}=1.36 \AA^{-1}$, which corresponds to the main $\mathrm{B}$ phase magnetic Bragg peak. This signal is not reproduced by spin wave calculations, and arguably may arise from trapped spins at domain boundaries. However, as the signal does not show any discrete feature as in [12], this remains speculative and needs further investigation.

Another possible scenario is that, at high temperature $\left(T>T_{N B}\right), J_{a}$ is close to a boundary between ferromagnetic and antiferromagnetic exchange. With AF superexchange along the chains being dominant, the system can oscillate between the two states A or B by just a flip of all the spins along a chain. This could lead to a B phase with a reduced ordered moment, hence supporting strong magnetic fluctuations, which cannot be taken into account classically, if they are low dimensional or longitudinal in nature [31]. Another possible consequence of the proximity of $\mathrm{J}_{\mathrm{a}}$ to such a boundary would be magnetic exchange disorder, which would lead to ill-defined and short-lived magnetic excitations.

Within this scenario, the fact that both $\mathrm{CaFe}_{2} \mathrm{O}_{4}$ and $\mathrm{CaCr}_{0.5} \mathrm{Fe}_{1.5} \mathrm{O}_{4}$, the latter of which has intrinsic exchange disorder, owing to the partial $\mathrm{Cr}$ to $\mathrm{Fe}$ substitution, show similar excitation spectra in the B phase, is an additional argument to further investigate the possibility for exchange disorder in these systems. However, as mentioned above, it should be noted that the 
diffraction data in the vicinity of the B phase is dominated by an energy integrated diffuse scattering, preventing the observation of the broadening of the magnetic Bragg peaks in $\mathrm{CaFe}_{2} \mathrm{O}_{4}$, which would arise from disorder-induced short-range correlations.

Additionally, in such a picture, $\mathrm{J}_{\mathrm{a}}$ would be expected to be very sensitive to local deviations from the average crystal structure. Indeed, in the non-substituted compound, when lowering the temperature, the diffraction data does show a magneto-elastic effect (see for instance the temperature evolution of the $a$ cell parameter in Figure $2 \mathrm{e}$ for $\mathrm{CaFe}_{2} \mathrm{O}_{4}$ ), which leads to changes in bond lengths and angles stabilising a ferromagnetic $\mathrm{J}_{a}$, and eventually an A type magnetic ordering at $\mathrm{T}_{\mathrm{NA}}$. Moreover, in agreement to [6], our study shows that small Cr substitution (up to $x=0.5$ at least) suppresses sign of magneto-elastic coupling (Figure $2 \mathrm{f}$ ) and thus prevents the A phase ordering altogether. These features are supporting evidence that the presence of a magneto-elastic effect could be key, as a subtle balance between bond distances and angles and the proximity of $\mathrm{J}_{\mathrm{a}}$ to an F-AF threshold may be at the core of the co-existence of the A and B phases. Considering $3 d^{5}-3 d^{5}$ interactions, both super-exchange and direct exchanges (with $90^{\circ}$ bond angles) are predicted to be antiferromagnetic, the only ferromagnetic contribution, coming from overlapping $p \sigma$ orbitals in for edge sharing octahedra, being weak [7]. In sharp contrast with the theory, ferromagnetic ordering of the $\mathrm{Fe}^{3+}$ moments is observed along the $c$ direction in both $\mathrm{x}=0$ and $\mathrm{x}=0.5$ compounds, which is mediated by an Fe-O-Fe bond angle close to $\sim 94^{\circ}$, for a $\mathrm{Fe}-\mathrm{Fe}$ distance of $\sim 3 \AA$. On the other hand, for the $\mathrm{J}_{a}$ exchange, larger $\mathrm{Fe}-\mathrm{Fe}$ distances $\left(\sim 3.1 \AA\right.$ ), and Fe-O-Fe angles $\sim 98^{\circ}$ are observed, supporting the idea of a competition between AF super-exchange and presumably ferromagnetic direct exchange in that configuration.

Also to be considered is a more complex Hamiltonian, with for instance, a second-neighbour ferromagnetic $\mathrm{J}$ ', likewise to $\beta-\mathrm{CaCr}_{2} \mathrm{O}_{4}$ [32]. A competition, between $\mathrm{J}_{\mathrm{a}}$ and $\mathrm{J}$ ' for example, would be in this case at the origin of a degeneracy of the ground state, and explain the unusual 
excitations of the B phase, linked in this case with a degree of magnetic frustration rather than with disorder. $\mathrm{CaFe}_{2} \mathrm{O}_{4}$ represents therefore an intriguing example, in which static and dynamic properties lead to standard 3D magnetic ordering and spinwaves at low temperature, but point towards conflicting behaviours in the intermediate temperature regime of the B phase. The discrepancies between the long-range static order and the complex nature of the fast fluctuating spin excitation highlight the need for a theoretical model beyond the classical spin wave analysis : more studies are in progress to model the B phase dynamics through a Monte-Carlo approach, in order to understand the exact nature of the A-B equilibrium in the RT ground state.

\section{CONCLUSION}

The investigation by neutron elastic and inelastic scattering of $\mathrm{CaFe}_{2} \mathrm{O}_{4}$ confirms the existence of two related magnetic phases in this compound, with very different dynamical characteristics : the dynamics of the low temperature ordered magnetic phase (A) can be understood simply with spin waves, using a first-neighbour exchange Hamiltonian, while in the intermediate B ordered magnetic phase, spin dynamics evade the classical approach. In the scenario that is discussed, the proximity of the interchain coupling to a ferromagnetic-antiferromagnetic boundary is responsible for magnetic exchange disorder, leading to a reduced ordered magnetic moment and non-conventional spin excitations in the B phase. Magneto-elastic effects are invoked to stabilize ferromagnetic inter-chain exchange away from the boundary, and to lead to A-type magnetic ordering at low temperature in $\mathrm{CaFe}_{2} \mathrm{O}_{4} . \mathrm{Cr}$ substitution $(\mathrm{x}=0.5)$, which introduces magnetic disorder owing to the random $\mathrm{Fe} / \mathrm{Cr}$ distribution on the magnetic sites,

stabilises the B phase only down to low temperature. That the magnetic excitation spectrum of $\mathrm{CaCr}_{0.5} \mathrm{Fe}_{1.5} \mathrm{O}_{4}$ in its $\mathrm{B}$ phase exhibits very similar features to that of $\mathrm{CaFe}_{2} \mathrm{O}_{4}$, and that magnetic 
fluctuations of the A type are also present in $\mathrm{CaCr}_{0.5} \mathrm{Fe}_{1.5} \mathrm{O}_{4}$ at temperatures between its magnetic ordering and the paramagnetic regime, both strongly substantiate the magnetic exchange disorder scenario.

\section{ACKOWLEDGMENTS}

The authors wish to express their thanks to Dr. E. Ressouche for inspiring discussions. 


\section{REFERENCES}

[1] P. Burlet and E. F. Bertaut, Comptes Rendus Hebdomadaires Des Seances De L Academie Des Sciences Serie B 264, 1208 (1967).

[2] P. Burlet and E. F. Bertaut, Comptes Rendus Hebdomadaires Des Seances De L Academie Des Sciences Serie B 264, 323 (1967).

[3] P. G. De Gennes, P. LAfore, and J. P. Millot, Journal of Physics and Chemistry of Solids 11, 105 (1959).

[4] H. Obermayer, H. DACHS, and H. Schrocke, Solid State Communications 12, 779 (1973).

[5] F. Damay, M. Poienar, C. Martin, A. Maignan, J. Rodriguez-Carvajal, G. Andre, and J. P. Doumerc, Physical Review B 80, 094410 (2009).

[6] L. M. Corliss, J. M. Hastings, and W. Kunnmann, Physical Review 160, 408 (1967).

[7] J. B. Goodenough, Magnetism and the Chemical Bond, Interscience, New York, 1963.

[8] M. C. Montmory, M. Belakhovsky, R. Chevalier, and R. Newnham, Solid State Communications 6, 317 (1968).

[9] E. F. Bertaut, J. Chappert, A. Apostolov, and V. Semenov, Bulletin De La Societe Francaise Mineralogie Et De Cristallographie 89, 206 (1966).

[10] Y. Allain, B. Boucher, P. Imbert, and M. Perrin, Comptes Rendus Hebdomadaires Des Seances De L Academie Des Sciences Serie B 263, 9 (1966).

[11] H. Watanabe, H. Yamauchi, M. Ohashi, M. Sugimoto, T. OKada, and M. Fukase, Journal Of The Physical Society Of Japan 22, 939 (1967).

[12] C. Stock， E. E. Rodriguez， N. Lee， M. A. Green， F. Demmel， R. A. Ewings, P. Fouquet, M. LAVer, C. Niedermayer, Y. Su, K. Nemkovski, J. A. RodrigueZ-Rivera, and S. . W. ChEOng, Physical Review Letters 117, 017201 (2016). 
[13] C. Stock, E. E. Rodriguez, N. Lee, F. Demmel, P. Fouquet, M. Laver, C. Niedermayer, Y. Su, K. Nemkovski, M. A. Green, J. A. RodrigueZ-Rivera, J. W. Kim, L. Zhang, and S. W. CheOng, Physical Review Letters 119, 257204 (2017).

[14] F. Damay, C. Martin, S. Petit, M. Songvilay, and E. Suard, High-resolution neutron diffraction study of polycrystalline CaFe2O4. Institut Laue-Langevin (ILL), doi:10.5291/ILL-DATA.5-24-587, 2016.

[15] J. Rodriguez-Carvajal, Physica B 192, 55 (1993).

[16] E. Kroumova, M. I. Aroyo, J. M. Perez-Mato, A. Kirov, C. Capillas, S. IVANTCHEV, and H. WondRATSCHEK, Phase Transitions 76, 155 (2003).

[17] F. Damay, C. Martin, S. Petit, S. Rols, M. Songvilay, and M. Zbiri, TOF inelastic neutron scattering study of polycrystalline CaFe2O4. Institut Laue-Langevin (ILL), doi:10.5291/ILL-DATA.4-01-1501, 2016.

[18] S. PETIT, Collection SFN 12, 105 (2011).

[19] J. H. HANnAY and J. F. NYE, Journal of Physics A-mathematical and General 37, PII S0305 (2004).

[20] B. F. DECKER and J. S. KASPER, Acta Crystallographica 10, 332 (1957).

[21] N. Kolev, M. N. Iliev, V. N. Popov, and M. Gospodinov, Solid State Communications 128, 153 (2003).

[22] R. D. SHAnnon, Acta Crystallographica Section A 32, 751 (1976).

[23] V. SkumryeV, M. Aroyo, and E. Ressouche, Private communication (2018).

[24] K. Obata, Y. Obukuro, S. Matsushima, H. Nakamura, M. Arai, and K. KoBAYASHI, Journal of the Ceramic Society of Japan 121, 766 (2013).

[25] S. Zouari, L. Ranno, A. Cheikh-Rouhou, M. Pernet, and P. Strobel, Journal of Materials Chemistry 13, 951 (2003). 
[26] M. Poienar, F. Damay, C. Martin, V. Hardy, A. Maignan, and G. André, Physical Review B 79, 014412 (2009).

[27] L. S. LobAnOvSKy and S. V. TRUKHANOv, Crystallography Reports 56, 482 (2011).

[28] R. Das, S. Karna, Y. C. LaI, and F. C. ChOU, Crystal Growth \& Design 16, 499 (2016).

[29] R. Das, S. Debnath, G. N. Rao, S. Narasimhan, and F. C. Chou, Phys. Rev. B 98, 144404 (2018).

[30] H. Yamamoto, T. Okada, H. Watanabe, and M. Fukase, Journal of the Physical Society of Japan 24, 275 (1968).

[31] M. Songvilay, E. E. Rodriguez, R. Lindsay, M. A. Green, H. C. Walker, J. A. Rodriguez-RIVERA, and C. StOcK, Phys. Rev. Lett. 121, 087201 (2018).

[32] F. Damay, C. Martin, V. Hardy, A. Maignan, C. Stock, and S. Petit, Physical Review B 84, 020402(R) (2011). 


\section{FIGURE CAPTIONS}

Figure 1 (color online) : (a) (top) Temperature evolution of the neutron diffraction patterns of $\mathrm{CaFe}_{2} \mathrm{O}_{4}$, (middle) Rietveld refinement of $\mathrm{CaFe}_{2} \mathrm{O}_{4}$ at $1.5 \mathrm{~K}$ in the $\mathrm{A}$ phase, (bottom) $\mathrm{A}$ magnetic structure in the $a b$ plane. (b) (top) Temperature evolution of the neutron diffraction patterns of $\mathrm{CaCr}_{0.5} \mathrm{Fe}_{1.5} \mathrm{O}_{4}$, (middle) Rietveld refinement of $\mathrm{CaCr}_{0.5} \mathrm{Fe}_{1.5} \mathrm{O}_{4}$ at $1.5 \mathrm{~K}$ in the $\mathrm{B}$ phase, (bottom) B magnetic structure in the $a b$ plane.

Main Bragg peaks and transition temperatures are indicated by symbols and dotted lines, in yellow/red for the B/A phases, respectively. For the refinements, experimental data are shown by open circles, calculated profile by a continuous line and allowed Bragg reflections by vertical marks. The difference between the experimental and calculated profiles is displayed at the bottom of each graph.

In the pictures of the magnetic structures, moments are aligned along $c$ and their direction is indicated by either $\mathrm{a}+$ or $\mathrm{a}-$ sign. The super-exchange chains (with $\mathrm{J}_{\mathrm{SE}}$ magnetic exchange) are outlined as dotted red lines. The coupling between edge-sharing octahedra, corresponding to $\mathrm{J}_{a}$, is outlined by a green ellipses. $\mathrm{J}_{a}$ is either antiferromagnetic (B phase), or ferromagnetic (A phase). The light/dark brown colouring of the octahedra distinguishes the two Fe Wyckoff sites.

Figure 2 (color online) : Temperature evolution of the $z f c$ and $f c$ magnetisation in 100 Gauss (top), of the magnetic site ordered moment value (middle) and of the cell parameter $a$ (bottom), for $\mathrm{CaFe}_{2} \mathrm{O}_{4}$ (left panels, in blue) and $\mathrm{CaCr}_{0.5} \mathrm{Fe}_{1.5} \mathrm{O}_{4}$ (right panels, in red).

Figure 3 (color online) : Magnetic excitations spectra of $\mathrm{CaFe}_{2} \mathrm{O}_{4}$ recorded at $230 \mathrm{~K}, 185 \mathrm{~K}$, and $50 \mathrm{~K}$ for incident wavelengths $\lambda_{\mathrm{i}}=1.1$ and $2.2 \AA$. Data have not been corrected by the 
detailed balance factor, and the maximum of the color scale varies by a factor 10 between 230 $\mathrm{K}$ and $50 \mathrm{~K}$. The dashed lines indicate the positions of the most intense magnetic Bragg peaks in the $\mathrm{B}$ phase (in yellow, at $\mathrm{Q}=1.36 \AA^{-1}$ ) and the A phase (in red, at $\mathrm{Q}=0.9 \AA^{-1}$ ).

Figure 4 (color online) : Magnetic excitations spectra of $\mathrm{CaFe}_{2} \mathrm{O}_{4}$ recorded at $230 \mathrm{~K}, 220 \mathrm{~K}$, $190 \mathrm{~K}, 180 \mathrm{~K}$ (a) and $170 \mathrm{~K}, 160 \mathrm{~K}, 130 \mathrm{~K}$ and $50 \mathrm{~K}$ (b) for incident wavelengths $\lambda_{\mathrm{i}}=4.1 \AA$. The dashed lines indicate the positions of the most intense magnetic Bragg peaks in the B phase (in yellow, at $\mathrm{Q}=1.36 \AA^{-1}$ ) and the A phase (in red, at $\mathrm{Q}=0.9 \AA^{-1}$ ). The arbitrary intensity scale maximum is 0.7 from $230 \mathrm{~K}$ to $180 \mathrm{~K}, 0.6$ for $170 \mathrm{~K}$ and $160 \mathrm{~K}, 0.3$ at $130 \mathrm{~K}$, and 0.1 at $50 \mathrm{~K}$.

Figure 5 (color online) : (a) $\mathrm{Q}=0.9 \AA^{-1}$ energy cuts in the magnetically ordered phase $\mathrm{A}$ of $\mathrm{CaFe}_{2} \mathrm{O}_{4}$, between $50 \mathrm{~K}$ and $170 \mathrm{~K}$. (b) Evolution with temperature of the gap in the A phase. (c) Corresponding $\mathrm{E}=-4 \mathrm{meV}$ cuts at $50 \mathrm{~K}, 130 \mathrm{~K}, 160 \mathrm{~K}$ and $230 \mathrm{~K}$ (detailed balance factor correction applied). Red (green) stars indicate main Bragg peaks in the A (B) phase. $\lambda_{\mathrm{i}}=4.1$ $\AA$.

Figure 6 (color online) : Comparison of INS data (detailed balance factor corrected) of $\mathrm{CaFe}_{2} \mathrm{O}_{4}$ at $50 \mathrm{~K}$ for $\lambda_{\mathrm{i}}=1.1 \AA$ (a) and $\lambda_{\mathrm{i}}=4.1 \AA$ (b) with spin wave calculations (c, d) (see text).

Figure 7 (color online) : (a) Inelastic scattering spectra of $\mathrm{CaCr}_{0.5} \mathrm{Fe}_{1.5} \mathrm{O}_{4}$ at $50 \mathrm{~K}$ and $150 \mathrm{~K}$, for two incident wavelengths $\lambda_{\mathrm{i}}=1.1 \AA$ and $2.2 \AA$. (b) Inelastic scattering spectrum of $\mathrm{CaCr}_{0.5} \mathrm{Fe}_{1.5} \mathrm{O}_{4}$ for constant $k_{f}=1.97 \AA^{-1}$ at $10 \mathrm{~K}$. (c) Energy scan at $\mathrm{Q}=1.36 \AA^{-1}$ (constant $k_{f}$ $=1.97 \AA^{-1}$ at $\left.10 \mathrm{~K}\right)$. 
Figure 8 (color online) $: \mathrm{E}=4 \mathrm{meV}$ cuts (from $\lambda_{\mathrm{i}}=2.2 \AA$ INS data, detailed balance factor correction applied) for (a) $\mathrm{CaFe}_{2} \mathrm{O}_{4}(\mathrm{x}=0)$ at $50 \mathrm{~K}, 185 \mathrm{~K}$ and $230 \mathrm{~K}$, (b) $\mathrm{CaCr}_{0.5} \mathrm{Fe}_{1.5} \mathrm{O}_{4}(\mathrm{x}=$ $0.5)$ at $2 \mathrm{~K}, 50 \mathrm{~K}$ and $150 \mathrm{~K}$ (c) $\mathrm{CaFe}_{2} \mathrm{O}_{4}$ and $\mathrm{CaCr}_{0.5} \mathrm{Fe}_{1.5} \mathrm{O}_{4}$ in their $\mathrm{B}$ phase $(185 \mathrm{~K}$ and $50 \mathrm{~K}$, respectively) and (d) $\mathrm{CaFe}_{2} \mathrm{O}_{4}$ and $\mathrm{CaCr}_{0.5} \mathrm{Fe}_{1.5} \mathrm{O}_{4}$ above their magnetic ordering temperatures ( $230 \mathrm{~K}$ and $150 \mathrm{~K}$, respectively). The dashed lines indicate the positions of the most intense magnetic Bragg peaks in the $\mathrm{B}$ phase (in green, at $\mathrm{Q}=1.36 \AA^{-1}$ ) and the $\mathrm{A}$ phase (in red, at $\mathrm{Q}$ $\left.=0.9 \AA^{-1}\right)$. 
(a) $\mathrm{CaFe}_{2} \mathrm{O}_{4}$
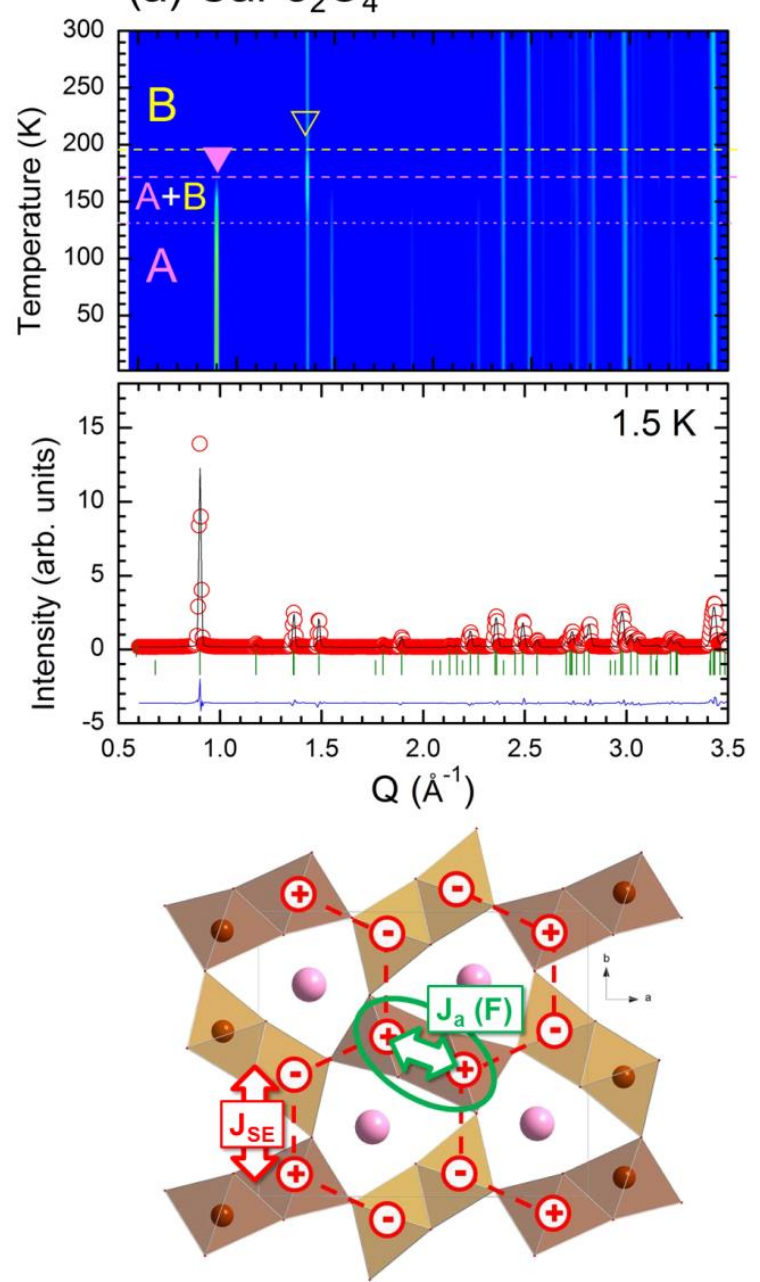

A phase (b) $\mathrm{CaCr}_{0.5} \mathrm{Fe}_{1.5} \mathrm{O}_{4}$
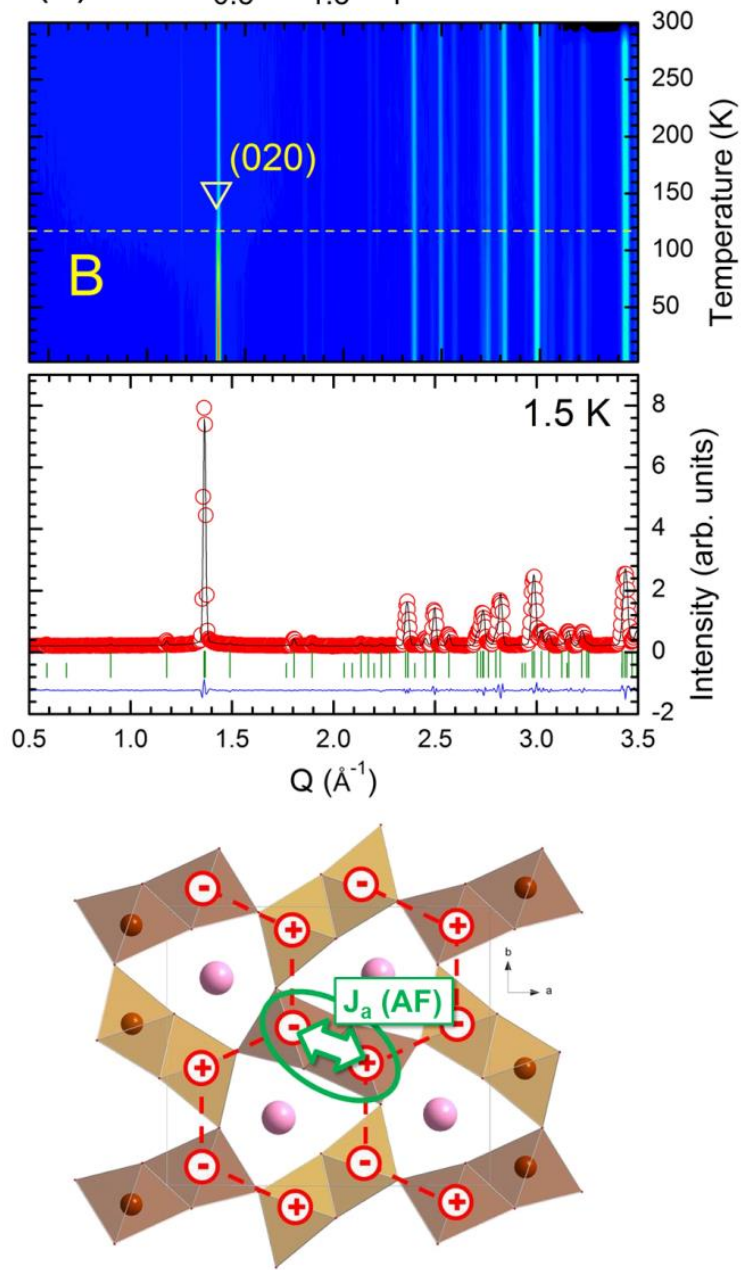

B phase

Figure 1 


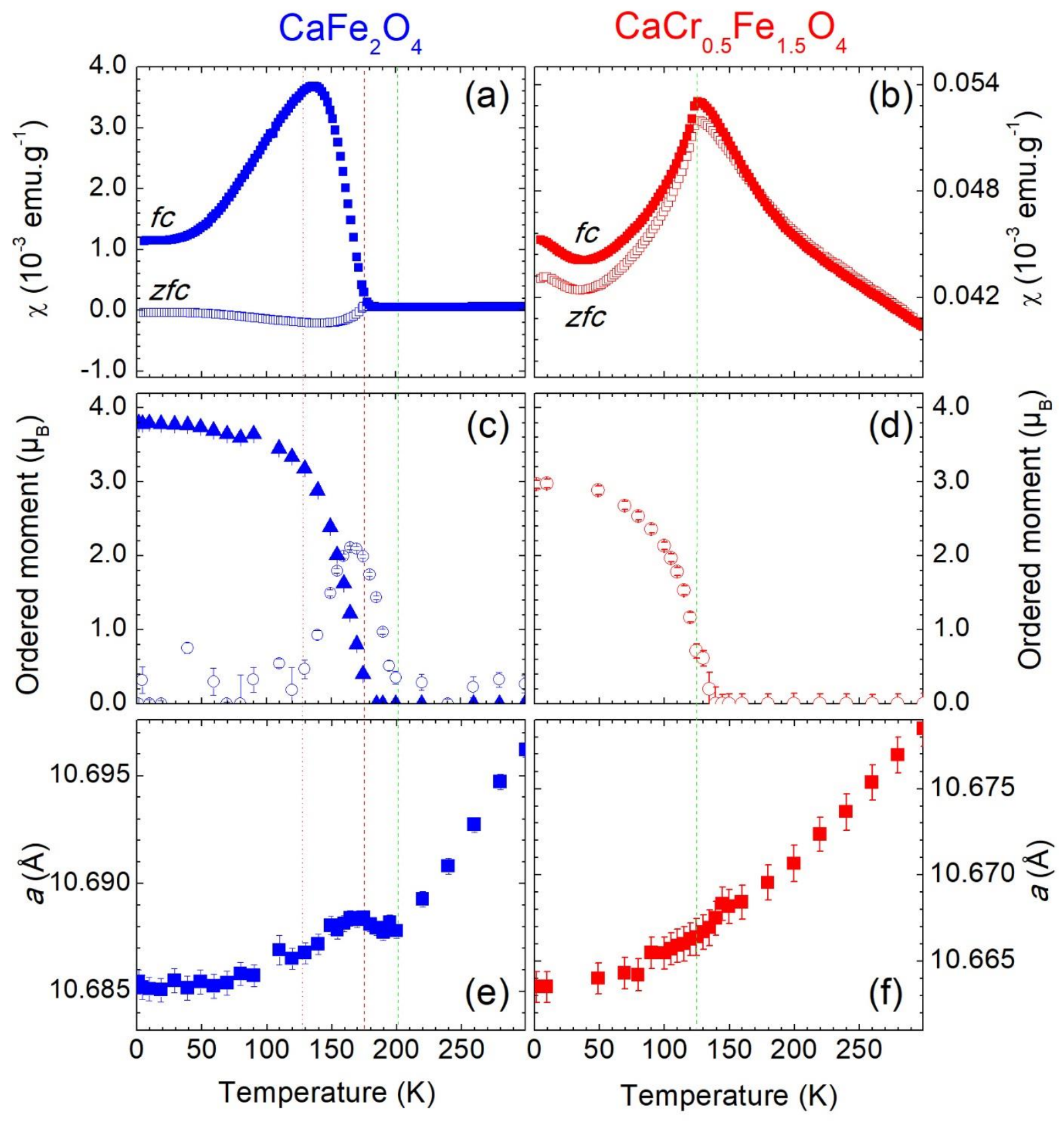

Figure 2 


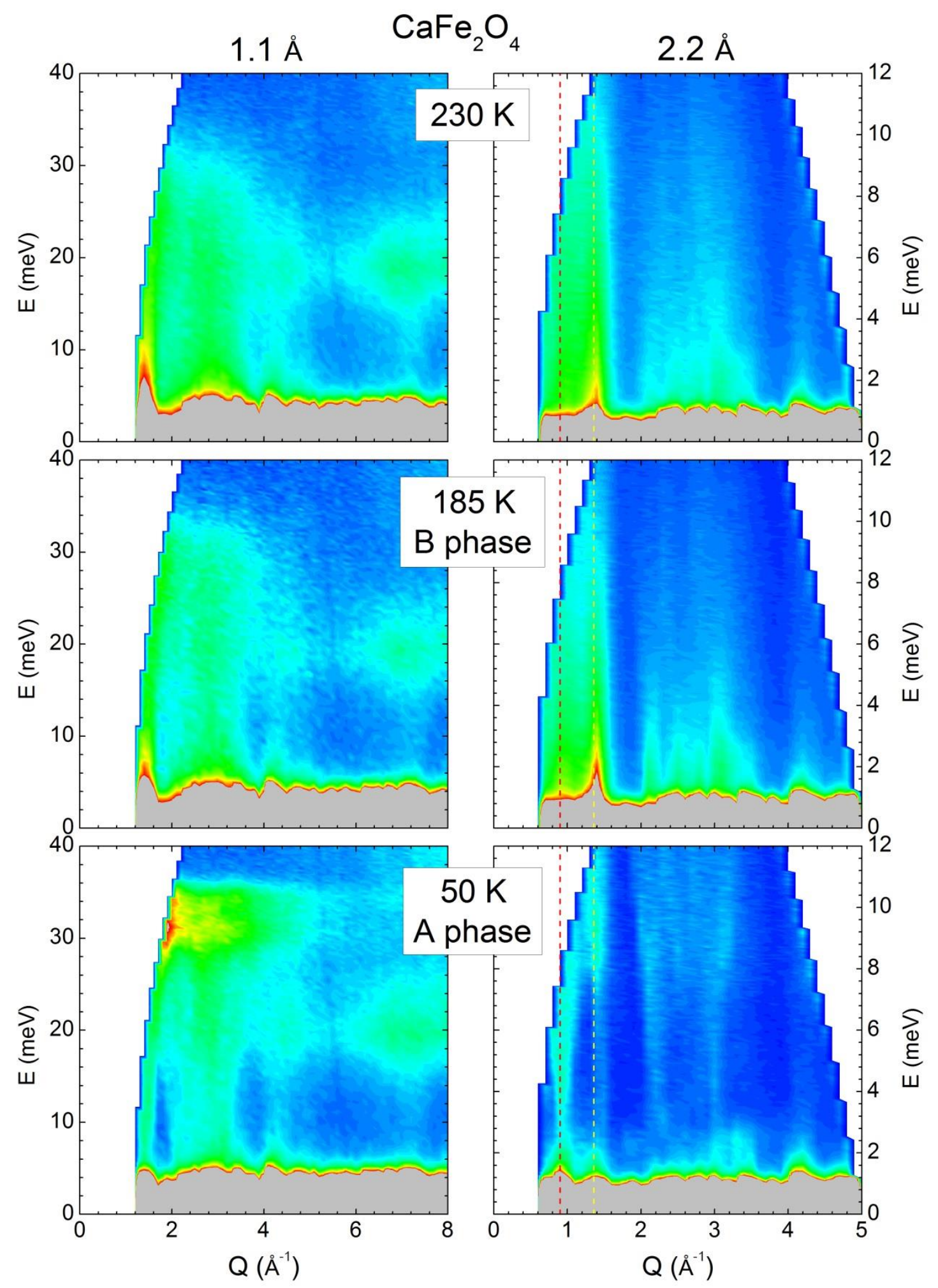

Figure 3 
(a) $\mathrm{CaFe}_{2} \mathrm{O}_{4}-\mathrm{T}>\mathrm{T}_{\mathrm{NA}}$
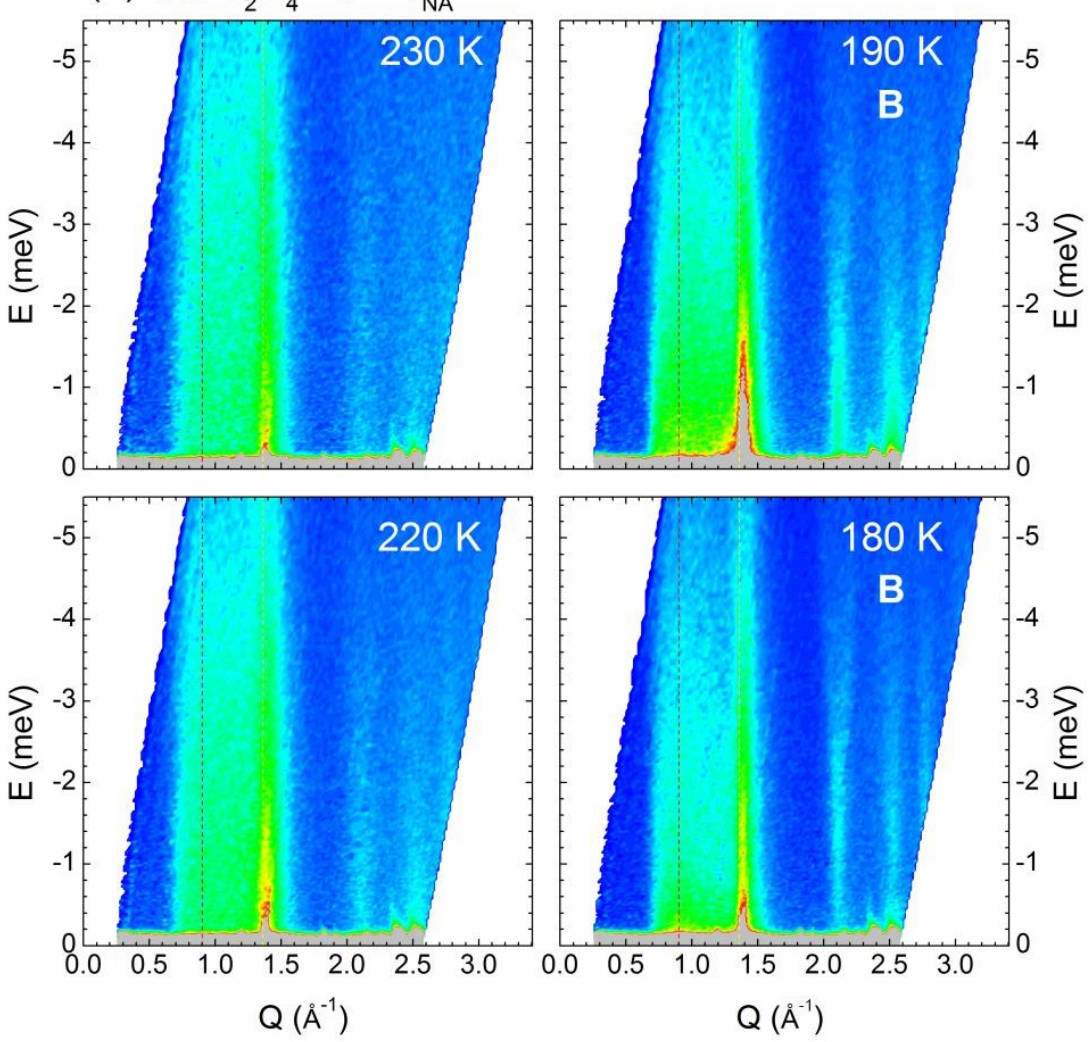

(b) $\mathrm{CaFe}_{2} \mathrm{O}_{4}-\mathrm{T}<\mathrm{T}_{\mathrm{NA}}$
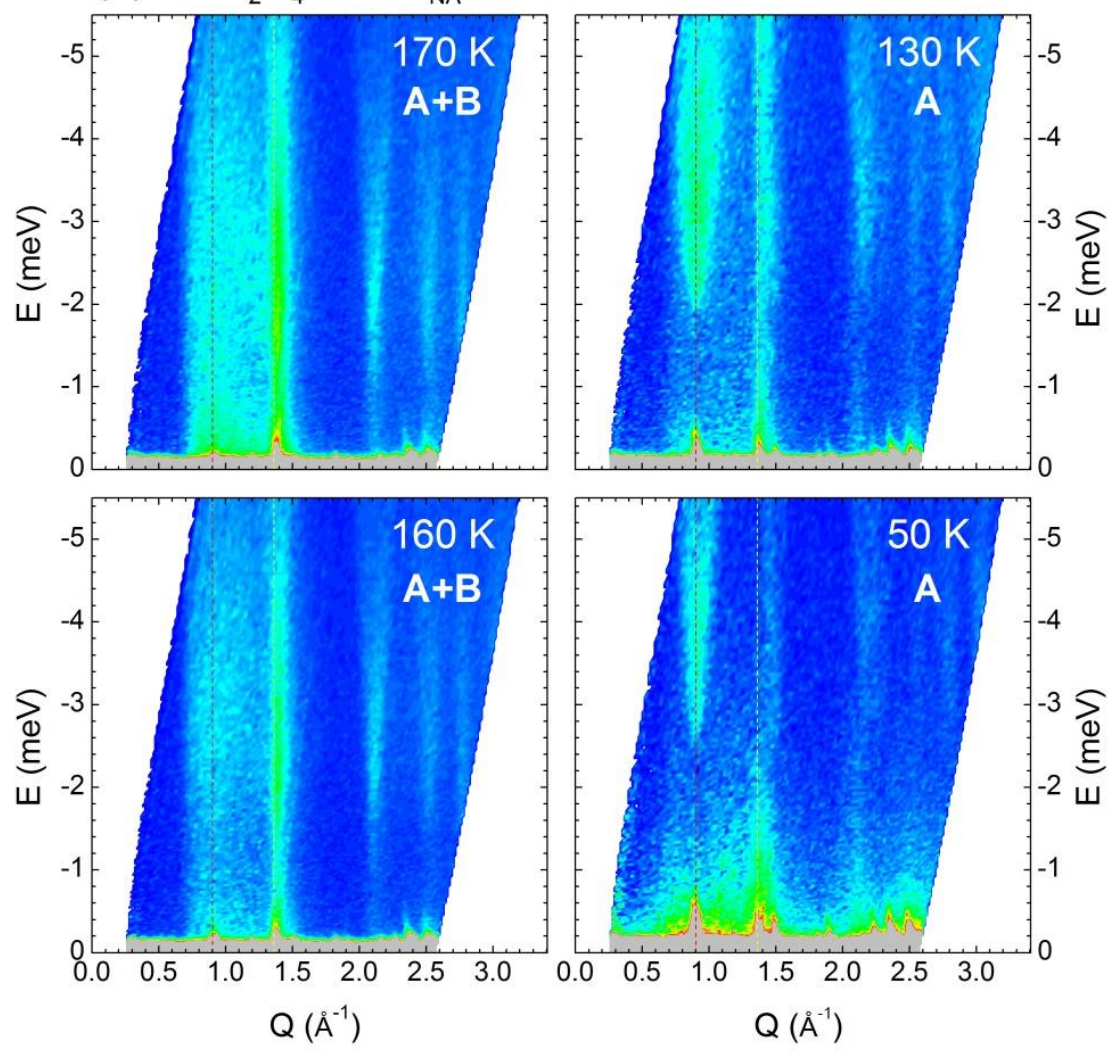

Figure 4 

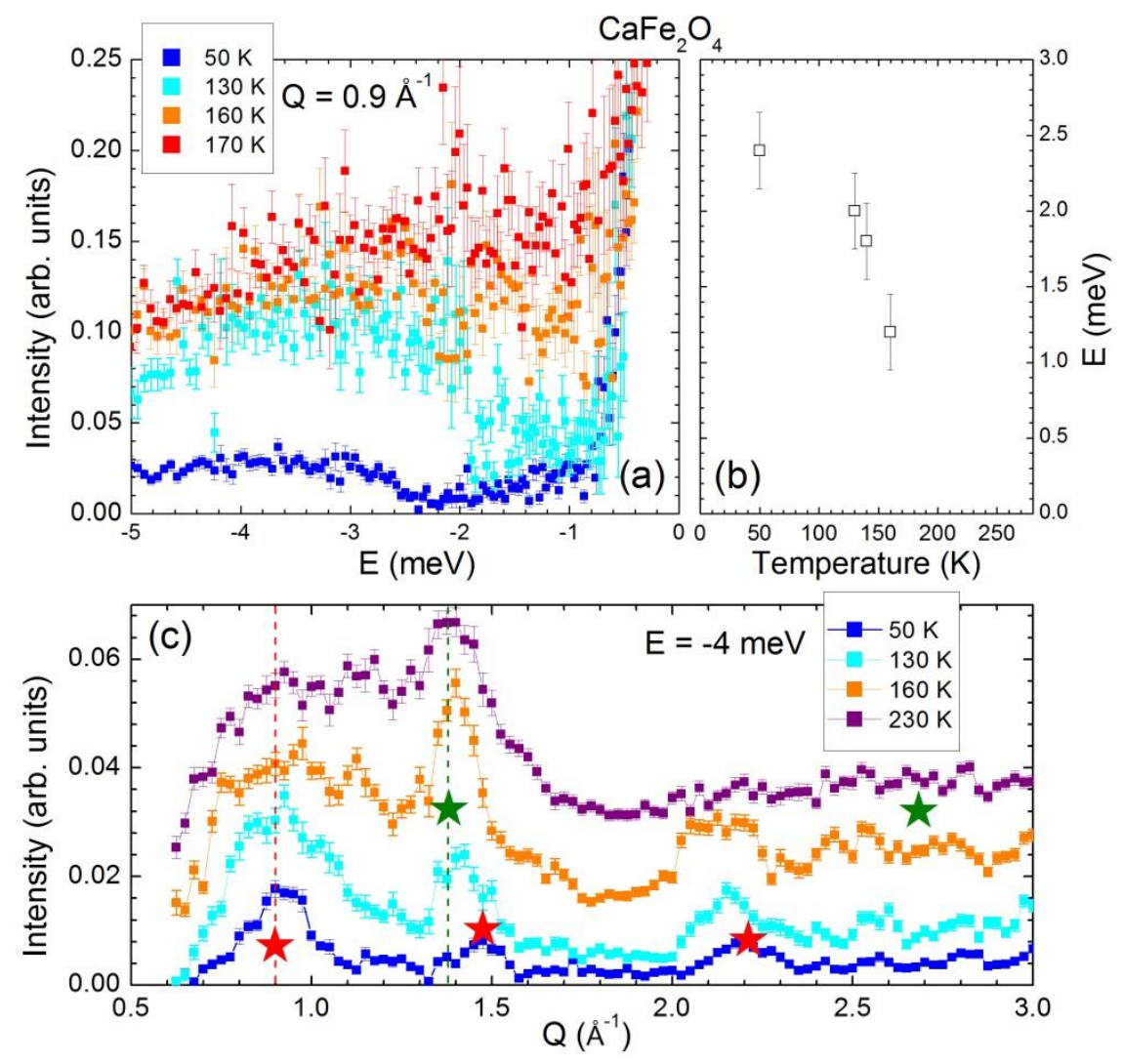

Figure 5 

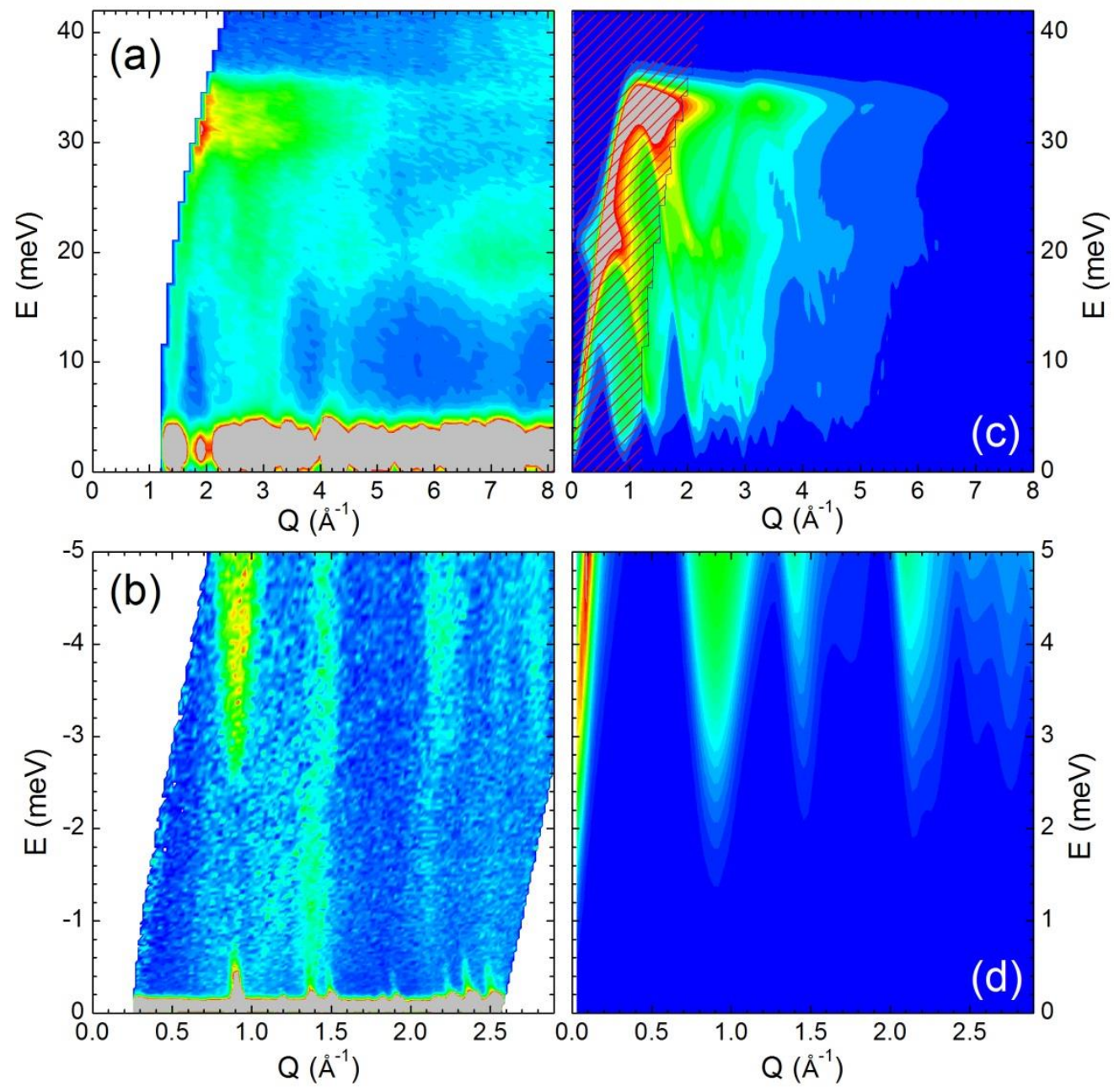

Figure 6 

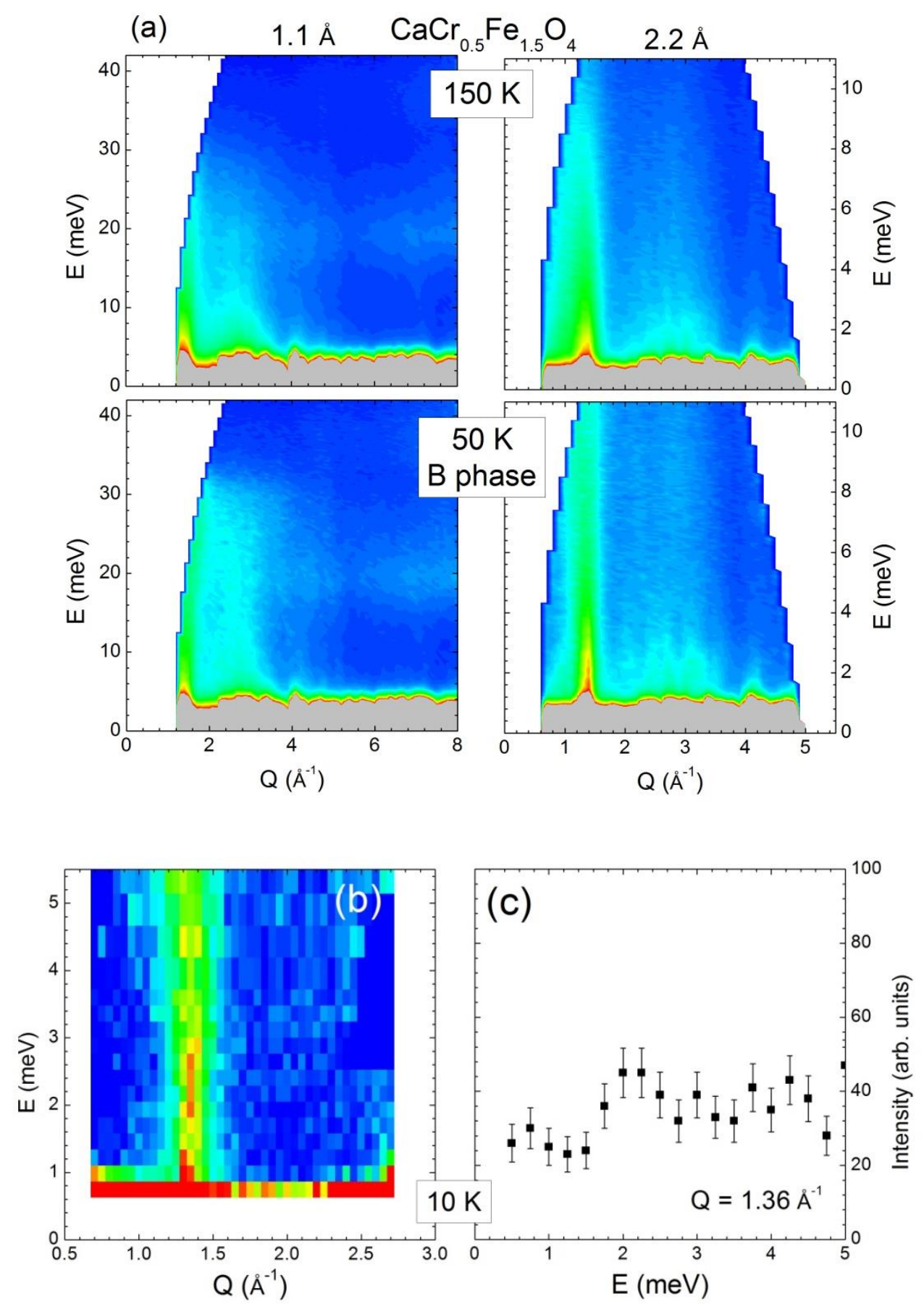

Figure 7 

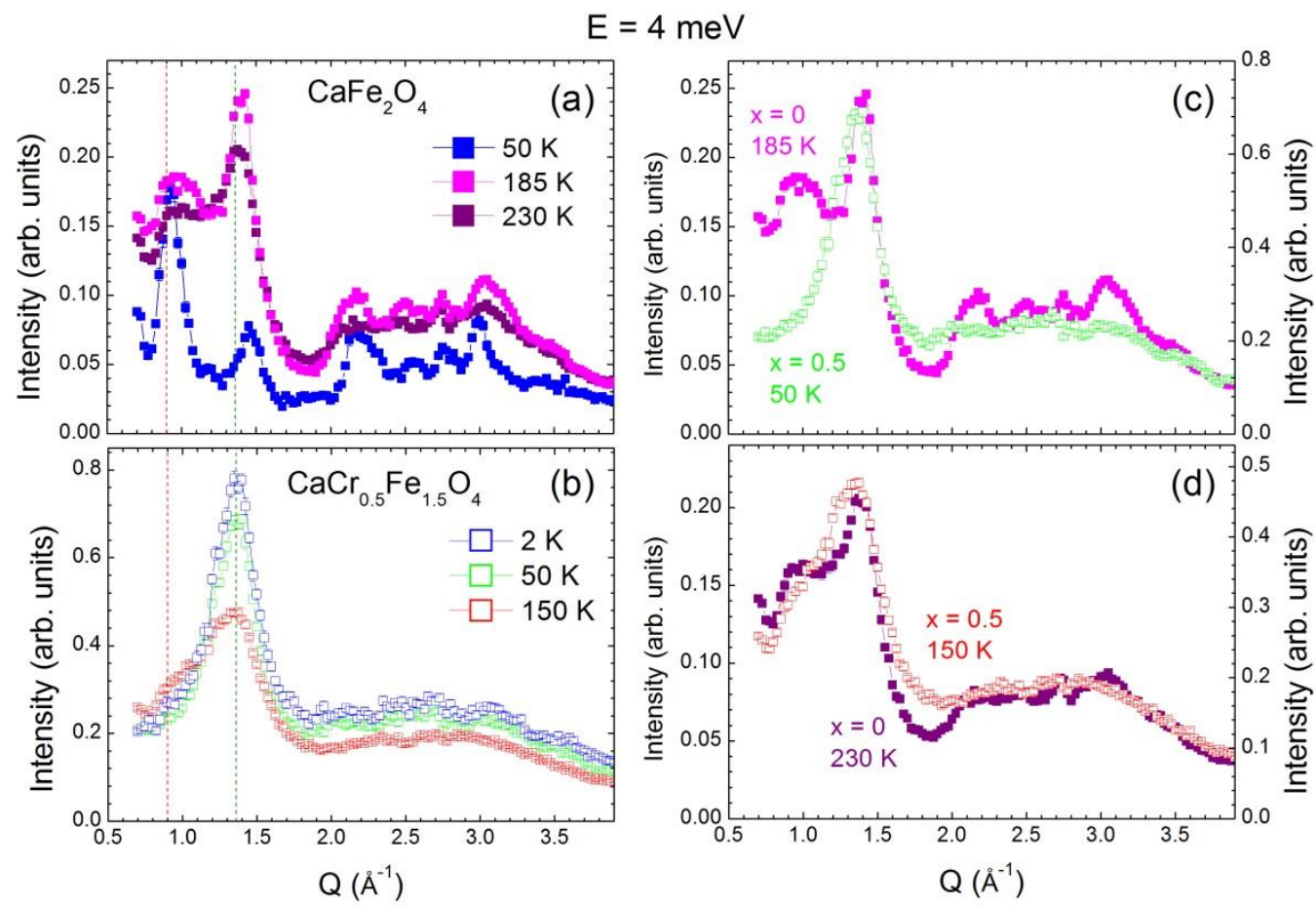

Figure 8 